Short research note

\title{
Antifouling activity of bioactive substances extracted from Holothuria scabra
}

\author{
Joseph Selvin ${ }^{1} \&$ A. P. Lipton ${ }^{2}$ \\ ${ }^{1}$ Department of Biotechnology, Malankara Catholic College, Mariagiri, Kaliakavilai-6291153, \\ Kanyakumari-District, India \\ E-mail: selvinj@rediffmail.com \\ ${ }^{2}$ Marine biotechnology laboratory, Central Marine Fisheries Research Institute, Vizhinjam Research Centre, \\ Vizhinjam - 695 521, Thiruvananthapuram, India
}

Received 19 February 2003; in revised form 22 July 2003; accepted 28 July 2003

Key words: foot adherence bioassay, antifouling compounds, Patella vulgata, Holothurian, Holothuria scabra

\begin{abstract}
Methanol extract of Holothuria scabra was tested for antifouling activity using 'mollusc foot adherence bioassay'. It was found that the secondary metabolites of $H$. scabra effectively prevented foot adherence of $P$. vulgata at various concentrations. Based on the present findings it could be inferred that the bioassay guided purification and fractionation may give forth potent novel antifouling compounds.
\end{abstract}

Fouling organisms cause serious problems in the cooling water systems of power stations and culture structures for oysters, seaweed, fish, etc., and a lot of effort has been made to find efficient antifouling substances. Fouling organisms usually do not colonize on the surfaces of sponges, echinoderm and corals since these organisms produce potent secondary metabolites including specific deterrents (Selvin, 2002). The mechanisms of secondary metabolites synthesis and chemical ecology are highly complicated and less explored. Marine animals can accumulate toxic substances released from either dead or living red tide organisms directly from the water or by eating other toxic diets through the food chain (Bakus, 1968; Bakus and Green, 1974; Bakus, 1982). The Holothuria contain rich sources of the toxic metabolite, holothurin or saponin (Jayasree et al., 1991). These toxic deterrents might form a rich source for developing potent novel antifoulants. This paper deals with the details of the findings of antifouling properties of secondary metabolites isolated from $H$. scabra.

Specimens of $H$. scabra were collected from seaweed infested rocky substratum off Muttom coast (southeast coast of India). The collected live speci- mens were transported to the laboratory in a 2501 high density plastic tank provided with constant aeration. They were killed under ice and washed in fresh water and dissected to remove the internal contents. For the isolation of secondary metabolites, the tissue was minced in a homogenizer (Omni, U.S.A.) and extracted three times with methanol and methanoldichloromethane (1:1). The combined extract was filtered and concentrated in a rotary vacuum evaporator (Buchi) at $40^{\circ} \mathrm{C}$.

The antifouling property of the isolated secondary metabolite was evaluated using 'foot adherence bioassay' developed by Selvin \& Lipton (2002). The assay plates $(100 \mathrm{~mm}$ petri plates) were spread evenly with $1 \mathrm{ml}$ of extract, which was subsequently evaporated to dry in a hot air oven at $40^{\circ} \mathrm{C}$. The plates were filled one-third with seawater without any disturbance to the extract layer. The limpets (Patella vulgata) were removed carefully from the tank and introduced into the triplicate experimental plates at the rate of 5 animals per plate. The immediate foot reflex and mobility were monitored continuously for until the foot shrunk. Based on the adherence (fouling) or shrinkage of the foot, the fouling rate was estimated. After the com- 


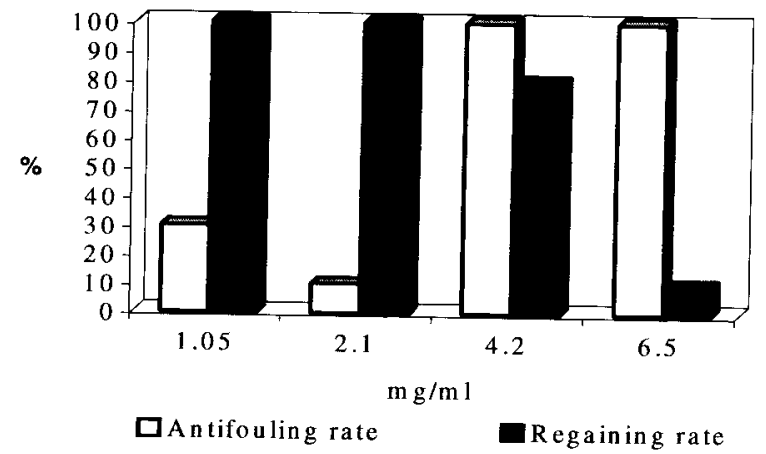

Figure 1. Antifouling activity of Holothuria scabra

pletion of exposure period, the treated animals were introduced in fresh seawater to observe their regaining rate.

In the present investigation, the secondary metabolite obtained from $H$. scabra was more potent in preventing the foot adherence of $P$. vulgata. The complete inhibition of foot adherence/fouling was observed at a concentration of $4.2 \mathrm{mg} / \mathrm{ml}$ (Fig. 1). This concentration was considered as a safe dose as $80 \%$ of the exposed $P$. vulgata were regained after the test period. However $H$. scabra was relatively more toxic at $6.5 \mathrm{mg} / \mathrm{ml}$, in which all the experimental animals were died.

As the submergible methods are highly timeconsuming and require substantial quantity of test compounds, reliable and effective primary assay systems are prerequisite for developing potent novel antifouling secondary metabolites. Although settlementbased microassay was used (Rittschof et al., 1985) for such purpose, the protocol based on the adult organisms was scanty. The reflex-based conventional 'foot stimulating' assay using the blue mussel Mytilus edulis galloprovincialis (Sera et al., 1999 a, b) was found ineffective. The foot was found stimulated even with seawater in many attempts made in our laboratory. Considering this lacuna, the assay was modified with a new 'foot adherence' technique to determine the activities of potent marine natural products. By principle, the fouling organisms require a suitable surface for their foot adherence. The attachment process involves recognition of the surface and production of biological adhesives that ensure attachment. Based on this principle, the present assay was developed, which was more effective over the conventional assay technique. Using the present bioassay system, potent antifouling substances were successfully isolated from sponges and seaweeds (Selvin, 2002).
Toxicity seems to help sessile or slow moving forms (Bakus et al., 1986). H. scabra also seems to be protected in this manner. $H$. atra metabolites were toxic to fish, mice and haemocytes (Rao et al., 1985). The pink glands referred to as 'Cuverian glands' of holothurians contain toxic substance, holothurin characterized as saponin (Nigrelli, 1952), which was found to be responsible for the potent toxicity or bioactivity. However according to Matsuno \& Ishida (1969) saponins are found in all parts of $H$. lecospilota. Other researchers have also reported the presence potent antifouling secondary metabolites in various holothurian species. According to Mokashe et al. (1994), the methanol extract of a $H$. leucospilota effectively prevented the growth of biofilm forming marine diatoms, Navicula subinflata and $N$. crucicula. The antifouling property of the extract of $H$. leucospilota was found to be species specific (Gonsalves, 1997). According to Nagabhushanam et al. (1994), the toxic effect and the $96 \mathrm{~h} \mathrm{LC50}$ values of $H$. leucospilota towards Caridina rajadhari decreased with increasing exposure period. The similar trend of increasing toxicity with time was observed in the present experiment. Therefore the bioassay guided purification and fractionation may give-forth potent antifoulants. The excess toxicity can be minimized through alteration of the functional groups.

\section{Acknowledgements}

Authors are thankful to Dr Mohan Joseph Modayil, Director and Dr R. Paul Raj, Head, PNP Division, CmFRI, Kochi for the facilities and encouragement. Help rendered by Shri. A. Udayakumar, Tech. Assist. CMFRI, Vizhinjam during the collection of specimens are thankfully acknowledged.

\section{References}

Bakus, G. J., 1968. Defensive mechanisms and ecology of tropical holothurians. Mar. Biol. 2: 23-32.

Bakus, G. J., 1981. Chemical defense mechanisms and fish behaviour on the Great Barrier Reef, Australia. Science 211: $497-499$

Bakus, G. J. \& G. Green, 1974. Toxicity in sponges and holothurians: a geographic pattern. Science 185: 951-987.

Bakus, G. J., N. M. Targett \& B. Schulte, 1986. Chemical ecology of marine organisms: an overview. J. Chem. Ecol. 12: 951-987.

Gonsalves, C. O. L., 1997. Effect of holothurian and zoanthid extracts on growth of some bacterial and diatom species. Ind. J. mar. Sci. 26: 377-379. 
Jayasree, V., R. Sen gupta \& P. V. Bhavanarayana, 1991. A toxin from Holothuria leucospilota (Brandt). In Thompson, M., F. Sarojini \& R. Nagabhushanam (eds), Bioactive Compounds from Marine Organisms with Emphasis on the Indian Ocean. An Indo-United States Symposium: 111-120.

Matsuno, T. \& Ishida, 1969. Seasonal variation in the saponin content of Holothuria leucospilota (Brandt). Experientia 25: 1261 .

Mokashe, S. S., A. Garg, A. C. Anil \& A. B. Wagh, 1994. Growth inhibition of periphytic diatoms by methanol extracts of sponges and holothurians. Ind. J. mar. Sci. 23: 57-58.

Nagabhushanam, R., B. A. Kumar \& R. Sarojini, 1994. Toxicity evaluation of the holothrian Holothuria (Mertensiothuria) leucospilota (Brandt) and the effect of toxin on the prawn Caridina rajadhari. In Rengarajan, K. \& D. B. James (eds), Proceedings of National Workshop on Beche-de-mer. CMFRI, Cochin, India. 46: 51-56.

Nigrelli, R. F., 1952. The effects of holothurian on fish and mice with sarcoma 180. Zoologica 37: 89-91.
Rao, D. S., D. B. James, K. G. Girijavallabhan, S. Muthuswamy \& M. Najumddin, 1985. Biotoxicity in echinoderms. J. mar. Biol. Ass. Ind. 27: 88-96.

Rittschof, D., I. R. Hooper, E. S. Branscomb, \& J. D. Costlow, (1985). Inhibition of barnacle settlement and behaviour by natural products from whip corals, Leptogorgia virgulata (Lamarck, 1815). J. Chem. Ecol. 11: 551-563.

Selvin, J., 2002. Shrimp disease management using secondary metabolites isolated from marine organisms. Ph.D thesis submitted to M.S. University, Tirunelveli, India. pp 204.

Selvin, J. \& A. P. Lipton, 2002. Development of a rapid 'mollusc foot adherence bioassay' for detecting potent antifouling bioactive compounds. Curr. Sci. 83: 735-737.

Sera, Y., K. Adachi \& Y. Shizuri, 1999a. A new epidioxy sterol as an antifouling substances from a Palauan marine sponge, Lendenfeldia chondrodes J. Nat. Products 62: 152-154.

Sera, Y., K. Adachi, F. Nishida \& Y. Schizuri, 1999b. A new sesquiterpene as an antifouling substance from a Palauan marine sponge Dysidea herbacea. J. Nat. Products 62: 395-396. 